\title{
In Vitro Transcription of Immunoglobulin Genes in a B-Cell Extract: Effects of Enhancer and Promoter Sequences
}

\author{
RANJAN SEN AND DAVID BALTIMORE* \\ Whitehead Institute for Biomedical Research, Cambridge, Massachusetts 02142,* and Department of Biology, \\ Massachusetts Institute of Technology, Cambridge, Massachusetts 02139
}

Received 27 May 1986/Accepted 7 January 1987

\begin{abstract}
Transfection experiments have led to the identification of three DNA sequences that are responsible for the tissue-specific expression of immunoglobulin genes. As a first step toward characterizing these regulatory phenomena at the biochemical level, we report the development of an in vitro transcription system from cells of the B lymphoid lineage. In these extracts, transcription of the MOPC41 $\mathrm{k}$ promoter is correctly initiated and dependent on the presence of an upstream sequence element located between -44 and -79 base pairs from the cap site. Second, although standard in vitro transcriptions are not affected by the presence or absence of enhancer sequences, we observed that the addition of polyethylene glycol led to a B-cell extract-specific suppression of transcription from a template that carries an immunoglobulin enhancer.
\end{abstract}

As part of the effort to understand tissue-specific activation and repression of genes, studies on the transcription of DNA transfected into tissue culture cells have begun to define sequences critical for regulating gene expression. For immunoglobulin genes, regulatory sequences have been localized at both the heavy- and the $\kappa$ light-chain loci. It has been established that the promoters of both the heavy- and light-chain immunoglobulin genes exhibit some tissue specificity (of about 10 - to 30 -fold) $(9,12,15,16,23)$. A second element is the tissue-specific enhancer $(3,4,14,16,27,29$, 31-34) located in the intron between the variable and constant regions. Although originally identified as sequences that dramatically increased the levels of transcription of transfected genes, enhancers have now been shown to exhibit other properties as well. For example, several recent reports $(19,43,44)$ claim that an enhancer on an endogenous heavy-chain gene may be lost without affecting the transcription level, implying a role for activation but not maintenance of a transcriptionally active state. Further, under certain cellular conditions, the simian virus 40 enhancer $(5,42)$ as well as the immunoglobulin enhancers (18) have been shown to have repressorlike properties. Finally, a third element has been implicated in the regulation of the heavy-chain gene, but not yet localized (16). Each element appears to be necessary but not sufficient for directing high-level, accurate transcription of a transfected gene. To further understand the roles of these individual elements, a functional in vitro assay would be of great value. Our first goal was, therefore, to derive transcription extracts from a B-lymphoid cell type.

Second, having accomplished that, we were able to examine the role of the immunoglobulin upstream sequence element in the in vitro transcription assay, finding that transcription of a rearranged $\kappa$ immunoglobulin gene template deleted of its upstream regulatory sequence is decreased about 10 -fold relative to the wild-type template. Third, under certain transcription conditions, templates carrying either the heavy-chain or the light-chain enhancer placed upstream from the cap site transcribed less efficiently than those templates deleted of enhancer sequences. This

* Corresponding author. effect was cis acting and present only in B-cell extracts derived from EW cells, but not in the heterologous HeLa cell extracts.

Our initial attempts to derive transcription extracts from B cells involved the mouse myeloma MPC 11. We found that neither whole-cell extracts (22) nor nuclear extracts (7) made from this cell line were capable of correctly initiating transcription from a template containing an immunoglobulin promoter. We were able to fractionate away an inhibitor and reconstitute a transcription system, but because the fractionation involved removing potentially important factors from the extract, we did not pursue mouse cells further. The fact that most standard transcription extracts are derived from HeLa cells, a human cell line, prompted us to examine extracts from human B-cell lines for their transcriptional activity. Whole-cell extracts were made from two human Burkitt lymphoma lines, EW and RAMOS, by the procedure of Manley et al. (22). As demonstrated below, these extracts were active.

The templates used for in vitro transcription reactions are diagrammed in Fig. 1A. The template representing the wild-type gene $(\mathrm{pK})$ was derived from the MOPC41 $\mathrm{k}$ gene and contained sequences from approximately 100 base pairs (bp) upstream from the transcription initiation site (endpoint $5^{\prime} \Delta 5$, Fig. 1A) to the $B g$ /II site in the major $J_{k}-C_{k}$ intron (25). This fragment retains the complete variable region which is rearranged to $J_{\kappa} 1$, but not the $\kappa$ enhancer which is further downstream of the $B g$ III site $(4,33,34)$. This short $5^{\prime}$ flank has been shown to be sufficient for accurate initiation and high-level transcription of the gene in a transient transfection assay (4). Deletion analysis of the $\kappa$ promoter showed previously that important regulatory sequences are present between nucleotides -79 and -44 because deletion $5^{\prime} \Delta 7$ completely abolished transcriptional competence of the gene while deletion $5^{\prime} \Delta 5$ had no effect (4). The template representing an inactive promoter mutant $(\mathrm{p} \Delta \mathrm{\kappa})$ was constructed by engineering a HindIII site into the $5^{\prime}$ end of $5^{\prime} \Delta 7$ and cloning the segment of the gene up to the $B g l$ II site into pUC13 cut with HindIII and BamHI.

To examine transcriptional activity in B-cell extracts, we did runoff transcription reactions at $30^{\circ} \mathrm{C}$ for $60 \mathrm{~min}$. A 

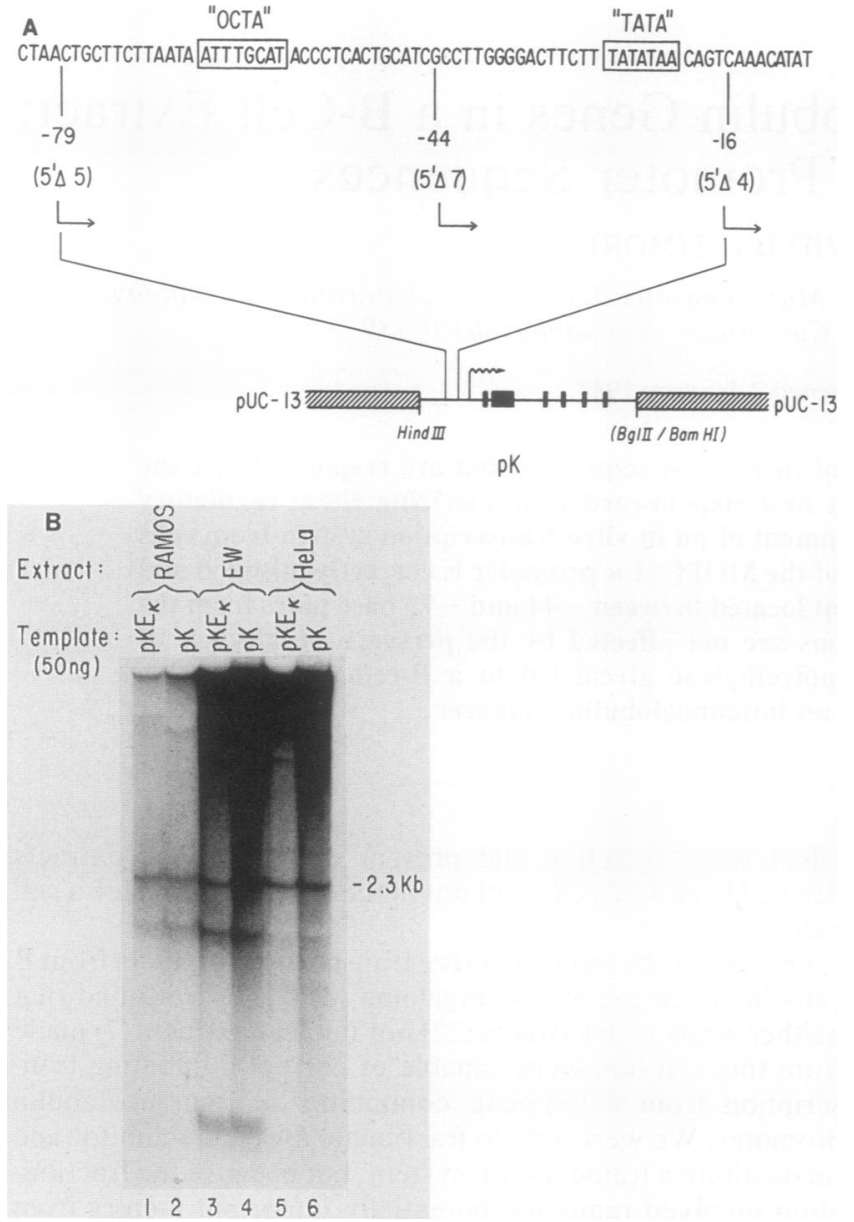

FIG. 1. In vitro transcription in human B-cell extracts. (A) DNA sequence of the promoter region of the MOPC41 $\kappa$ gene. The deletions $5^{\prime} \Delta 5$ and $5^{\prime} \Delta 7$ have been described before (4). The highly conserved octanucleotide sequence which is found upstream of all sequenced heavy- and light-chain variable-region genes is boxed (labeled OCTA). It is located approximately $30 \mathrm{bp}$ upstream from the TATA box. The plasmids $\mathrm{p} \kappa$ and $\mathrm{p} \Delta \kappa$ were constructed by converting the $5^{\prime}$ ends of $5^{\prime} \Delta 5$ and $5^{\prime} \Delta 7$ into a HindIII site with synthetic linkers followed by cloning the fragment up to the BglII site in the $\mathrm{J}_{\mathrm{k}}-\mathrm{C}_{\mathrm{k}}$ major intron into HindIII-BamHI-digested pUC13. $\mathrm{pKE}_{\mathrm{k}}$ and $\mathrm{pKE} \mathrm{E}_{\mu}$ represent plasmids containing either the $\kappa$ enhancer or the heavy-chain enhancer cloned into the unique HindIII site of pK. The segments used as the enhancers are an 800-bp HindIII$M b o I I$ fragment from the $\mathrm{J}_{\kappa}-\mathrm{C}_{\kappa}$ intron (25) and a 700-bp XbaI-EcoRI fragment from the $\mathrm{J}_{\mathrm{H}}-\mathrm{C}_{\mu}$ intron $(3,14)$. (B) Transcription in wholecell extracts made from the human B lymphoma cell lines RAMOS (lanes 1 and 2) and EW (lanes 3 and 4) and from HeLa cells (provided by A. Fire; lanes 5 and 6 ). The templates were linearized at the SacI site in the polylinker, and the expected $2.3-\mathrm{kb}$ runoff transcript is indicated.

typical reaction mix contained $9 \mu l(160 \mu \mathrm{g})$ of whole-cell extract, $50 \mu \mathrm{M}$ each ATP, CTP, and GTP, $0.5 \mu \mathrm{M}$ UTP, 10 $\mu \mathrm{Ci}$ of $\left[\alpha-{ }^{32} \mathrm{P}\right] \mathrm{UTP}(7,600 \mathrm{Ci} / \mathrm{mol}), 5 \mathrm{mM}$ creatine phosphate, $0.3 \mathrm{mg}$ of creatine phosphokinase (Sigma Chemical Co., St. Louis, Mo.) per ml, $12 \mathrm{mM}$ HEPES ( $N$-hydroxyethylpiperazine- $N^{\prime}$-2-ethanesulfonic acid) (pH 7.9), $12 \%$ glycerol, 60 $\mathrm{mM} \mathrm{KCl}, 5 \mathrm{mM} \mathrm{Mg}{ }^{2+}, 1 \mathrm{mM}$ EDTA, $0.6 \mathrm{mM}$ dithiothreitol, linearized template $(\sim 50 \mathrm{ng})$, and poly $(\mathrm{dI}-\mathrm{dC})(\sim 400 \mathrm{ng})$. After work up, the RNAs were glyoxalated and analyzed by electrophoresis through a $1.4 \%$ agarose gel in $10 \mathrm{mM}$ sodium phosphate (pH 6.8)-1 mM EDTA (22). A runoff transcript of 2.3 kilobases $(\mathrm{kb})$ was evident when RAMOS, EW, or HeLa cell extracts were used (Fig. 1B, lanes 2,4 , and 6). When a $\kappa$-chain enhancer sequence was added to the construct, no effect was evident, implying that transcription in these extracts is enhancer independent (Fig. 1B, lanes 1, 3, and 5). (In EW and HeLa cells, the enhancer appears to cause a slight increase in the background radioactivity but not in the 2.3-kb band.) The band at $2.3 \mathrm{~kb}$ could be abolished by not adding the template or by transcribing in the presence of 0.5 $\mu \mathrm{g}$ of $\alpha$-amanitin per $\mathrm{ml}$. Thus it represents a templatespecific RNA polymerase II transcript. The band just below $2.3 \mathrm{~kb}$ is not decreased by $\alpha$-amanitin and presumably reflects end labeling of endogenous $18 \mathrm{~S}$ rRNA.

To assess whether initiation of transcription occurred at the natural cap site, we used a second assay (17). For this assay, the uniformly labeled RNA was hybridized to a single-strand DNA probe spanning the transcription initiation site (generated by cloning the PvuII-Sau3A [33] fragment of the $\kappa$ gene into bacteriophage M13). The resulting complex was digested with RNase $T_{1}$, and the RNase-

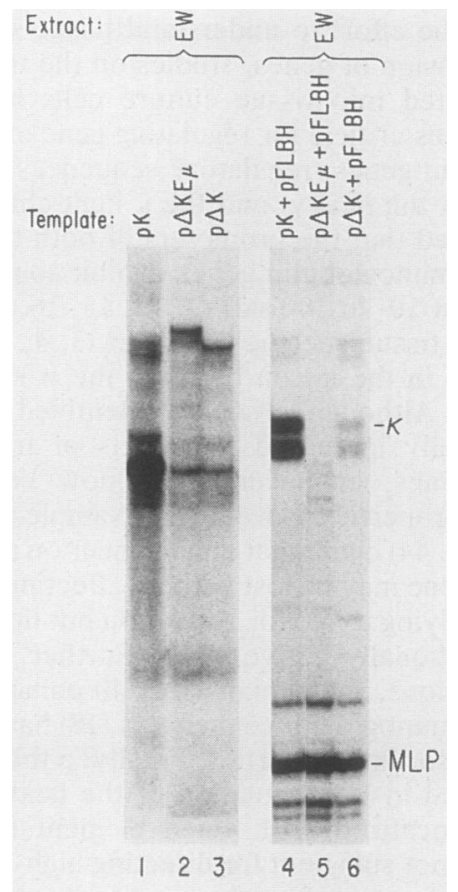

FIG. 2. Effect of the upstream deletion $5^{\prime} \Delta 7$ on in vitro transcription in B-cell extracts utilizing a preincubation pulse-chase protocol. Runoff transcripts were obtained with templates containing either the wild-type promoter (lane 1 ) or the truncated $\kappa$ promoter (lanes 2 and 3). Lanes 4 to 6 , In vitro transcription with closed circular templates containing the wild-type promoter (lane 4) or the truncated $\kappa$ promoter (lanes 5 and 6 ). In these reactions $50 \mathrm{ng}$ of a closed circular template containing the adenovirus major late promoter (MLP) was included as an internal control. The transcripts specific to the $\kappa$ template or the adenovirus template are indicated as $\kappa$ and MLP, respectively. For a template containing the major late promoter we used the plasmid pFLBH which contains sequences from 14.7 to 17.0 map units of adenovirus inserted between the BamHI and HindIII sites of pBR322 (kind gift of A. Fire and M. Samuels). The upper of the two bands ( $k$ ) derived from the immunoglobulin promoter represents the correct start for $\kappa$ transcription. The lower band is seen at variable intensities and probably does not represent a different cap site, as explained in the text. 
resistant RNA fragments were analyzed by electrophoresis through a $6 \%$ polyacrylamide gel with $8.3 \mathrm{M}$ urea. Analysis of in vitro-synthesized RNA by this method is shown in Fig. 2 (lane 4). The upper band (labeled $k$ ) represents the correct cap site. The band just below it was seen at variable intensities (e.g., see Fig. 3D) and probably does not represent a different cap site but rather arises from cleavage with RNase $T_{1}$ at the next $G$ residue from the $3^{\prime}$ end of the protected region. (Examination of the sequence near the Sau3A1 site [33] shows that the second set of $G$ residues on the RNA lies 19 bp upstream from the end of the region of homology with the single-stranded DNA probe.) Thus, the extracts generated from B cells were capable of correctly initiating and transcribing the immunoglobulin promoter in vitro with approximately the same efficiency as a HeLa cell extract.

To analyze the effect of 5 -flanking sequences in vitro, we examined the transcription of the deleted gene, $p \Delta \kappa$. Because many regulatory effects act on the rate of initiation of transcription, we chose to use a preincubation, pulse-chase protocol which measures initiation rates (11). Either the linearized or the supercoiled template $(50 \mathrm{ng})$ was incubated in a volume of $20 \mu \mathrm{l}$ with $9 \mu \mathrm{l}(\sim 160 \mu \mathrm{g})$ of EW extract, $6 \%$ (wt/vol) polyethylene glycol (PEG) 20,000, and all other components described above except the nucleotides for 60 min at $30^{\circ} \mathrm{C}$. Transcription was then initiated by the addition of nucleotides and radiolabeled UTP (final concentration, 60 $\mu \mathrm{M}$ each ATP, CTP, and GTP, $1 \mu \mathrm{M}$ UTP, and $10 \mu \mathrm{Ci}$ of $\left.\left[\alpha^{-32} \mathrm{P}\right] U T \mathrm{~T}\right)$. The initiating pulse was maintained for $10 \mathrm{~min}$ at $30^{\circ} \mathrm{C}$ followed by a 10 -min chase with a vast excess of nonradioactive nucleotides (final concentrations, $330 \mu \mathrm{M}$ ATP, CTP, and GTP, $1 \mathrm{mM}$ UTP). The reactions were quenched, and the transcripts were analyzed by electrophoretic separation. Incorporated radioactivity in this assay is proportional to the number of correct initiations occurring during the pulse. In Fig. 2, comparison of lanes 2 and 3 with lane 1 shows that the template pк, which contains about 100 bp upstream of the initiation site, initiated approximately 10 -fold more efficiently than did the deletion mutant $\mathrm{p} \Delta \kappa$. Again, the presence of the heavy-chain enhancer placed at $-44 \mathrm{bp}$ to the truncated promoter did not alter the level of transcription. (The upper band present in all lanes presumably arises from end-to-end transcription of the linearized plasmid which is often observed in such reactions and is independent of the presence of regulatory sequences). When closed circular templates were used, a similar effect of the promoter truncation was observed (Fig. 2, lanes 4 to 6). In these reactions a template containing the major late promoter of adenovirus was included as an internal control (28). Major late promoter-specific transcripts were detected with the M13 clone XH11 (provided to us by A. Fire and M. Samuels), and the expected protected RNA fragment of 180 bp is labeled MLP. Comparison of lanes 5 and 6 with lane 4 shows that there was a 10-fold decrease in the efficiency of transcription from the mutant promoter, whereas the transcript of the major late promoter remained constant. The reason for the apparent decrease in the amount of transcription from the supercoiled template containing the heavychain enhancer was not further addressed. It is evident, however, that the dependence of transcription on an upstream sequence between -44 and -79 is observed whether the template is linear or circular. To assess whether the effect described above was specific to B-cell extracts, we transcribed the same templates in the heterologous $\mathrm{HeLa}$ whole-cell extract. A four- to fivefold decrease in transcription was seen with the deleted template when compared with the wild-type template (data not shown). Thus, the effect of the deletion is, at best, only modestly tissue specific.

In EW cell extracts, the same level of RNA was generated from two templates, one carrying and one deleted of the immunoglobulin $\kappa$ enhancer (Fig. 1B). This was true in HeLa extracts as well and was independent of whether the template was linear or closed circular (data not shown). In attempts to show enhancer effects in vitro, we varied a number of obvious conditions individually, e.g., $\mathrm{Mg}^{2+}$, $\mathrm{Ca}^{2+}, \mathrm{NH}_{4}{ }^{+}$, spermidine, time, but none of these conveyed any template selectivity. However, as described below, the addition of PEG to the transcription reaction did lead to a suppression of transcription from a template carrying either the heavy- or light-chain enhancer.

The plasmid pBRK was constructed by cloning the $2-\mathrm{kb}$ $P v u I I-B g l I I$ fragment of the rearranged MOPC41 $\kappa$ gene containing the promoter, variable region, and extra $\mathrm{J}_{\mathrm{k}}$ segments in pBR322. The $\kappa$ enhancer, present on an 800-bp HindIII-MboII fragment of the $J_{k}-C_{k}$ intron (25), was inserted into the unique HindIII site in pBRK to generate the plasmid pBRKE ${ }_{k}$ (Fig. 3A). The orientation of the insert was determined by cleaving with AvaII which cuts once within the enhancer and placed the essential $250 \mathrm{bp}$ (marked by the cross-hatched box) approximate 600 bp away from the cap site. The plasmid $\mathrm{pKE}_{\mu}$ (Fig. 3B) was constructed from plasmid pK by adding the 700-bp XbaI-EcoRI heavy-chain complete enhancer fragment from the $J_{\mu}-C_{\mu}$ intron (16) upstream of the start site of transcription at the unique HindIII site. The orientation of this insert placed the essential 300 bp (marked by the cross-hatched box) that retains 30 to $50 \%$ of the enhancer activity approximately $130 \mathrm{bp}$ away from the cap site.

To probe the effects of the enhancer sequences on the initiation step of the transcription reaction, we again followed the preincubation pulse-chase protocol. When the two sets of plasmids described above were used as templates for in vitro transcription reactions in the presence of $6 \% \mathrm{PEG}$ 20,000 , a striking difference in the extent of RNA produced from each template was observed (Fig. 3C). The presence of either the $\kappa$ enhancer (lanes 1 and 2) or the heavy-chain enhancer (lanes 3 and 4) on a template led to a suppression of transcription from that template. Most interestingly, this effect was limited to transcription in a B-cell extract because when the same templates were transcribed in a HeLa cell extract, no difference in the levels of RNA was observed (lanes 5 and 6). Use of closed circular plasmids as DNA templates yielded the same results. In a B-cell extract, the plasmid containing the heavy-chain enhancer transcribed 5to 10-fold less efficiently (Fig. 3D, lane 1) than a plasmid lacking an enhancer (lane 2). Use of a plasmid (pFLBH) containing the adenovirus major late promoter as an internal control showed that the extent of transcription of this promoter (lanes 1 and 2, labeled MLP) remained constant. The repressive effect of the immunoglobulin enhancer was observed only in the B-cell extract and not in HeLa extracts (Fig. 3D, lanes 3 and 4). This effect was reproducibly observed if the transcription conditions were kept constant with a given cell extract. To observe maximal suppression with an independently derived extract from the same cell line, we often had to adjust the ratios of DNA template and protein in the extract. This negative enhancer effect in B-cell extracts was observed in the range of 50 to $150 \mathrm{mM} \mathrm{KCl}$, but was lost if the protein concentration in the reaction was decreased by a factor of 4 from its optimal concentration. Although transcription reactions in HeLa cell extracts were done under a wide variety of different conditions, we never 

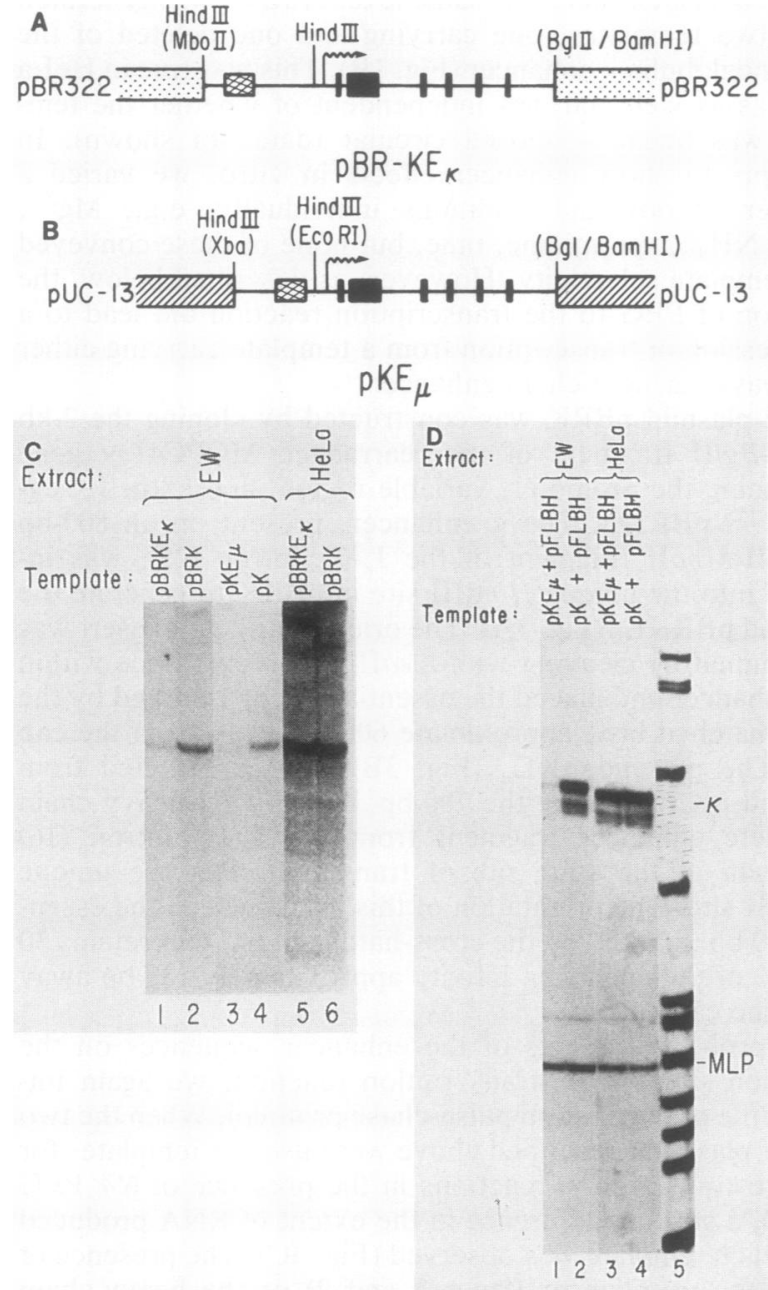

FIG. 3. Plasmids utilized for in vitro transcription reactions and effect of immunoglobulin enhancer sequences in vitro. (A) $p B R K E_{k}$ is a plasmid carrying the $\kappa$ enhancer which was derived from $\mathrm{pBRK}$ as described in the text. The cross-hatched box represents the essential $250 \mathrm{bp}$ of the $\kappa$ enhancer. $\mathrm{pBRK}$ and $\mathrm{pBRKE} \mathrm{E}_{\mathrm{k}}$ were linearized for runoff transcription assays by cutting with Sall in the pBR322 backbone. (B) $\mathrm{pKE}_{\mu}$ is a $\mu$ enhancer-bearing plasmid and was derived from $\mathrm{p}_{\kappa}$ (Fig. 1A). The cross-hatched box represents the essential $300 \mathrm{bp}$ of the $\mu$ enhancer. Plasmids $\mathrm{pK}$ and $\mathrm{pKE}_{\mu}$ were linearized for runoff transcription assays by cutting with SacI in the polylinker. (C) Effect of immunoglobulin enhancer sequences on in vitro transcription with linear templates. Runoff transcripts were obtained with $\mathrm{pBRKE} \mathrm{E}_{\mathrm{k}}$ and $\mathrm{pBRK}$ as templates in B-cell extracts (lanes 1 and 2) or in a HeLa cell extract (lanes 5 and 6) or with pKE ${ }_{\mu}$ and $\mathrm{pK}$ as templates in a B-cell extract (lanes 3 and 4). (D) Effect of immunoglobulin enhancer sequences on in vitro transcription with closed circular templates and the preincubation pulse-chase protocol. $\kappa$-gene-specific radioactive RNA was selected by hybridization to a single-stranded DNA probe spanning the initiation site of transcription. A plasmid containing the adenovirus major late promoter was included as an internal control in all transcription reactions, and the resultant RNA is labeled MLP. RNA (labeled $\kappa$ ) was synthesized from templates with and without the immunoglobulin heavy-chain enhancer in a B-cell extract (lanes 1 and 2) and in a HeLa extract (lanes 3 and 4). Lane 5, End-labeled, HpaII-digested pBR322 DNA.

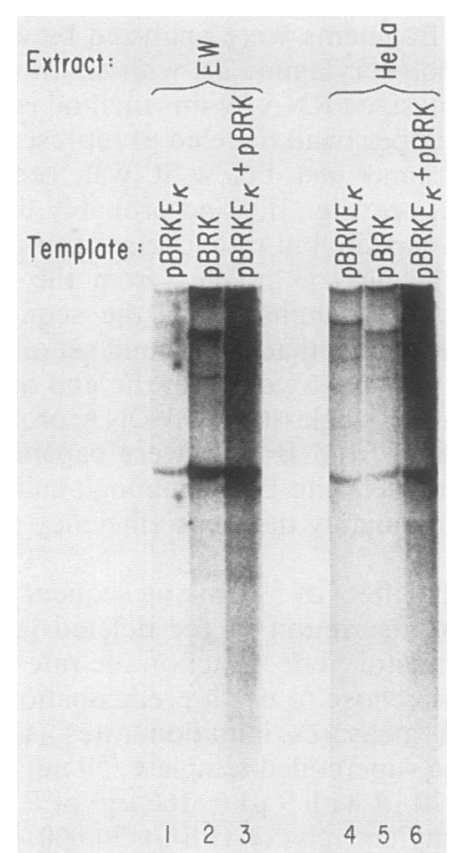

FIG. 4. Runoff transcription analysis of the effect of mixing templates with and without the $\kappa$ enhancer sequence. Approximately $50 \mathrm{ng}$ each of linearized templates $\mathrm{pBRKE} \mathrm{E}_{\kappa}$ and $\mathrm{pBRK}$ were transcribed individually (lanes 1 and 2 , respectively) or as an equimolar mixture (lane 3 ) in a B-cell extract or in a HeLa cell extract (lanes 4, 5, and 6). Transcriptions were done with $45 \%$ ( $\mathrm{vol} / \mathrm{vol})$ whole-cell extract and $25 \mu \mathrm{g}$ of poly $(\mathrm{dI}-\mathrm{dC}) \cdot$ poly $(\mathrm{dI}-\mathrm{dC})$ per $\mathrm{ml}$ in the presence of $6 \%$ (wt/vol) PEG 20,000 following the preincubation, pulse-chase protocol. The in vitro-synthesized RNA was glyoxalated and analyzed by electrophoresis through a $1.4 \%$ agarose gel.

detected differential transcription of templates as a consequence of the presence of an immunoglobulin enhancer.

To examine whether the suppression of transcription was mediated in cis upon the template carrying the enhancer, we did experiments mixing templates $\mathrm{pBRK}$ and $\mathrm{pBRKE} \mathrm{K}_{\mathrm{k}}$ in the same reaction. If the suppression described earlier was due to depletion of some limiting transcription factor by binding to the enhancer sequences, then a second template in the reaction should also be adversely affected (i.e., in trans). However, this was not so (Fig. 4). A negative effect of the presence of the enhancer on the transcription of linearized templates $\mathrm{pBRK}$ and $\mathrm{pBRKE} \mathrm{E}_{\mathrm{k}}$ in individual reactions was observed (Fig. 4, lanes 1 and 2). However, when both templates were present simultaneously in the same transcription reaction, the amount of RNA observed was similar to that observed with pBRK alone (compare lanes 3 and 2), thus showing that transcription of this template was not repressed owing to its presence in the same reaction as pBRKE $\mathrm{k}_{\mathrm{k}}$. When the same experiment was done in a HeLa extract, once again the results were additive (Fig. 4, lanes 4 , 5 , and 6). In this case there was no $\mathrm{pBRKE}_{\mathrm{k}}$ templatespecific repression, thus yielding runoff transcripts of equiv-

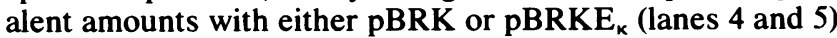
and approximately double the amount in the mixed transcription reaction (pBRK and PBRKE $E_{k}$ ) (lane 6). Furthermore, the fact that the levels of transcripts initiating from the major late promoter (Fig. 3D) were unchanged in the presence of both plasmids pBRK and $\mathrm{pBRKE}_{\mathrm{k}}$ also argues against the negative effect being mediated in trans by the depletion of some limiting transcription factor. We therefore 
suggest that the observed repressive effect is cis acting upon the plasmid that carries an immunoglobulin enhancer sequence and is specific to an extract derived from a B lymphoid cell.

We reported here the development of transcriptionally competent whole-cell and nuclear extracts from two independent human B-cell lymphomas which should be useful for the biochemical analysis of tissue-specific regulatory phenomena. In such extracts, transcription from the promoter of the MOPC41 $\kappa$ gene was correctly initiated, and a promoter deletion significantly reduced the level of initiated RNA. Furthermore, in the presence of $6 \%$ PEG, templates carrying either the $\mu$ or $\kappa$ enhancer transcribed less efficiently than those deleted of enhancer sequences. This suppressive effect was restricted to B-cell extracts only and not observed in heterologous HeLa cell extracts. These effects may now be used as functional assays during purification of the putative factors that mediate them and thus set the stage for a more refined biochemical and mechanistic analysis of immunoglobulin gene transcription.

The sequences responsible for the tissue selectivity of the immunoglobulin promoters have been narrowed down to a 150-bp fragment for the $V_{H}$ promoter (16) and a 220-bp fragment for the $V_{k}$ promoters $(12,15)$. A strikingly conserved octanucleotide sequence (ATTTGCAT) motif appears in these fragments and has been postulated to be a recognition sequence for a tissue-specific regulatory protein $(10,30)$. It is curious, therefore, that deletion of this sequence causes similar effects on the amounts of transcripts generated in vitro in either B-cell extracts or the heterologous HeLa extract. This observation, however, is consistent with the observation that both EW cells and HeLa cell nuclear extracts contain a factor that binds specifically over this sequence (41). Further, the same octamer sequence motif has been shown to be of importance for the regulation of non-B-cell-specific genes as well, e.g., the U1 and U2 small nuclear RNA genes $(1,24)$. Therefore, it is not surprising that it binds a non-tissue-specific factor.

Hydrophilic polymers such as PEG and polyvinyl alcohol have been essential components of in vitro replication reactions in crude extracts (13) and more recently have been used to increase the efficiency of in vitro splicing reactions (20). These polymers are believed to have two effects on these reactions. First, they promote the concatenation of DNA into large aggregates (21) induced presumably by initial condensation, and second, they increase the local concentration of all macromolecules by an excluded volume effect that has been called macromolecular crowding (45). What the role of PEG is in bringing about an enhancer-dependent suppression of in vitro transcription is not clear. It is conceivable that compaction may make it easier for distant sections of the DNA to interact with each other, and macromolecular crowding may help bring about the binding of relatively rare proteins with these sequences. Recently, the simian virus 40 enhancer $(35-37,40)$ and the immunoglobulin $\mu$ enhancer $(2,37)$ have been shown to have a positive effect on in vitro transcriptions. Examinations of the conditions required to observe an enhancement in vitro shows (i) the need to concentrate the nuclear extract and (ii) a strong dependence on the presence of spermidine. Since the latter is believed to promote condensation of DNA, the combination should lead to conditions rather similar to those generated in our reactions by the addition of PEG.

The paradoxical nature of extract-specific suppression of in vitro transcription from a template carrying an immunoglobulin enhancer requires some speculative explanation.
Even in experiments with the simian virus 40 enhancer only a subset of the functional characteristics of that enhancer have been mimicked in vitro. This has led to the argument that perhaps an enhancer can operate at various levels (39), and at the present state of refinement of in vitro systems only a few of these can be mimicked simultaneously. More specifically, there is evidence to suggest that functional activation of an enhancer is a multicomponent phenomenon in which there is a need for tissue-specific as well as nonspecific trans-acting factors $(26,38)$. One possibility is that we are reconstituting only partial function under our assay conditions by only a subset of these factors interacting with the enhancer, thus giving rise to the unexpected observed inhibition. Further, it has recently been shown that both the simian virus $\mathbf{4 0}$ and immunoglobulin enhancers are the sites of negative regulation of transcription under certain cellular conditions $(5,18,42)$. Perhaps our in vitro conditions mimic more closely these inhibitory conditions rather than those that give enhancement. Another possibility is that binding of the correct set of factors is inducing an inappropriate function because our assay is biased by our preconceived notion of what the function of an enhancer is. For example, if the role of the protein bound to the $\mu$ enhancer $(6,8)$ is not to serve as an entry site for RNA polymerase but rather to define nuclear localization or to change chromatin structure, then its effect in vitro would not necessarily be seen as an increase in the number of polymerase molecules accurately initiating transcription during the pulse in our experiments.

We thank Andrew Fire, Mark Samuels, and Phillip Sharp for their enthusiasm and help in initiating this project and for generously providing us with major late promoter-containing recombinant plasmids and HeLa whole-cell extracts, David Weaver for critical reading of the manuscript, and Ginger Pierce for quick and efficient typing of the manuscript. Deletions $5^{\prime} \Delta 5$ and $5^{\prime} \Delta 7$ were a gift from Yehudit Bergman.

This work was supported by a grant from the American Cancer Society to D.B. R.S. is a fellow of the Damon Runyon-Walter Winchell Cancer Fund.

\section{LITERATURE CITED}

1. Ares, M., Jr., M. Mangin, and A. M. Weiner. 1985. Orientationdependent transcription activator upstream of a human U2 snRNA gene. Mol. Cell. Biol. 5:1560-1570.

2. Augereau, P., and P. Chambon. 1986. The mouse immunoglobulin heavy chain enhancer: effect on transcription in vitro and binding of proteins present in HeLa and lymphoid B cell extracts. EMBO J. 5:1791-1797.

3. Banerji, J., L. Olson, and W. Schaffner. 1983. A lymphocyte specific cellular enhancer is located downstream of the joining region in immunoglobulin heavy chain genes. Cell 33:729-740.

4. Bergman, Y., D. Rice, R. Grosschedl, and D. Baltimore. 1984. Two regulatory elements for $K$ immunoglobulin gene expression. Proc. Natl. Acad. Sci. USA 81:7041-7045.

5. Borrelli, E., R. Hen, and P. Chambon. 1984. Adenovirus-2 EIA products repress enhancer-induced stimulation of transcription. Nature (London) 312:608-612.

6. Church, G. M., A. Ephrussi, W. Gibert, and S. Tonegawa. 1985. Cell type specific contacts to immunoglobulin enhancers in nuclei. Nature (London) 313:798-801.

7. Dignam, J. D., R. M. Lebowitz, and R. G. Roeder. 1983. Accurate transcription initiation by RNA polymerase II in a soluble extract from isolated mammalian nuclei. Nucleic Acids Res. 11:1475-1489.

8. Ephrussi, A., G. M. Church, S. Tonegawa, and W. Gilbert. 1985. B lineage-specific interactions of an immunoglobulin enhancer with cellular factors in vivo. Science 227:134-140.

9. Falkner, F. G., E. Neumann, and H. Zachau. 1984. Correct transcription of an immunoglobulin $\kappa$ gene requires an upstream 
fragment containing conserved sequence elements. HoppeSeyler's Z. Physiol. Chem. 365:1331-1343.

10. Falkner, F. G., and H. G. Zachau. 1984. Tissue specificity of the initiation of immunoglobulin $\kappa$ gene transcription. Nature (London) 310:71-74

11. Fire, A., M. Samuels, and P. A. Sharp. 1984. Interactions between RNA polymerase II, factors and template leading to accurate transcription. J. Biol. Chem. 259:2509-2516.

12. Foster, J., J. Stafford, and C. Queen. 1985. An immunoglobulin promoter displays cell-type specificity independently of the enhancer. Nature (London) 315:423-425.

13. Fuller, R. S., J. M. Kaguni, and A. Kornberg. 1981. Enzymatic replication of the origin of the Escherichia coli chromosome. Proc. Natl. Acad. Sci. USA 78:7370-7374.

14. Gillies, S. D., S. L. Morrison, V. T. Oi, and S. Tonegawa. 1983. A tissue specific enhancer is located in the major intron of a rearranged immunoglobulin heavy chain gene. Cell 33:717-728.

15. Gopal, V. T., T. Shimada, A. W. Baur, and A. W. Nienhuis. 1985. Contribution of promoter to tissue-specific expression of the mouse immunoglobulin kappa gene. Science 229:1102-1104.

16. Grosschedl, R., and D. Baltimore. 1985. Cell type specificity of immunoglobulin gene expression is regulated by at least 3 DNA sequence elements. Cell 41:885-897.

17. Hansen, U., and P. A. Sharp. 1983. Sequences controlling in vitro transcription of SV40 promoters. EMBO J. 2:2293-2303.

18. Hen, R., E. Borelli, and P. Chambon. 1985. Repression of the immunoglobulin heavy chain enhancer by the adenovirus-2 E1A products. Science 230:1391-1394.

19. Klein, S., F. Sablitzky, and A. Radbruch. 1984. Deletion of the IgH enhancer does not reduce immunoglobulin heavy chain production of a hybridoma IgD class switch variant. EMBO J. 3:2473-2476.

20. Krainer, A. R., T. Maniatis, B. Ruskin, and M. R. Green. 1984. Normal and mutant human $\beta$-globin pre-mRNAs are faithfully and efficiently spliced in vitro. Cell 36:993-1005.

21. Low, R. L., J. M. Kaguni, and A. Kornberg. 1984. Potent catenation of supercoiled and gapped DNA circles by topoisomerase 1 in the presence of a hydrophilic polymer. $\mathbf{J}$. Biol. Chem. 259:4576-4581.

22. Manley, J. L., A. Fire, A. Cano, P. A. Sharp, and M. L. Gefter. 1980. DNA-dependent transcription of adenovirus genes in a soluble whole-cell extract. Proc. Natl. Acad. Sci. USA 77: 3855-3859.

23. Mason, J. O., G. T. Williams, and M. S. Neuberger. 1985. Transcription cell type specificity is conferred by an immunoglobulin $\mathrm{V}_{\mathrm{H}}$ gene promoter that includes a functional consensus sequence. Cell 41:479-487.

24. Mattaj, I. W., S. Lienhard, J. Jiricny, and E. M. De Robertis. 1985. An enhancer-like sequence within the Xenopus U2 gene promoter facilitates the formation of stable transcription complexes. Nature (London) 316:163-167.

25. Max, E. E., J. V. Maizel, and P. Leder. 1981. The nucleotide sequence of a 5.5 kilobase DNA segment containing the mouse $\kappa$ immunoglobulin $J$ and $C$ region genes. J. Biol. Chem. 256: 5116-5120.

26. Mercola, M., J. Goverman, C. Mirell, and K. Calame. 1985. Immunoglobulin heavy chain enhancer requires one or more tissue specific factors. Science 227:266-270.

27. Mercola, M., X.-F. Wang, J. Olsen, and K. Calame. 1983. Transcriptional enhancer elements in the mouse immunoglobulin heavy chain locus. Science 221:663-665.
28. Miyamoto, N. G., V. Moncollin, M. Wintzerith, R. Hen, J. M. Egly, and P. Chambon. 1984. Stimulation of in vitro transcription by the upstream element of the adenovirus-2 major late promoter involves a specific factor. Nucleic Acids Res. 12:8779-8799.

29. Neuberger, M. S. 1983. Expression and regulation of immunoglobulin heavy chain gene transfected into lymphoid cells. EMBO J. 2:1373-1378.

30. Parslow, T. G., D. L. Blair, W. J. Murphy, and D. K. Granner. 1984. Structure of the 5'-ends of immunoglobulin genes: a novel conserved sequence. Proc. Natl. Acad. Sci. USA 81:2650-2654.

31. Picard, D., and W. Schafiner. 1984. A lymphocyte specific enhancer in the mouse immunoglobulin kappa gene. Nature (London) 307:80-82.

32. Potter, H., L. Weir, and P. Leder. 1984. Enhancer-dependent expression of human $\kappa$ immunoglobulin genes introduced into mouse pre-B lymphocytes by electroporation. Proc. Natl. Acad. Sci. USA 81:7161-7165.

33. Queen, C., and D. Baltimore. 1983. Immunoglobulin gene transcription is activated by downstream sequence elements. Cell 33:741-748.

34. Queen, C., and J. Stafford. 1984. Fine mapping of an immunoglobulin gene activator. Mol. Cell. Biol. 4:1042-1049.

35. Sassone-Corsi, P., J. P. Dougherty, B. Wasylyk, and P. Chambon. 1984. Stimulation of in vitro transcription from heterologous promoters by the SV40 enhancer. Proc. Natl. Acad. Sci. USA 81:308-312.

36. Sassone-Corsi, P., A. Wildeman, and P. Chambon. 1985. A trans-acting factor is responsible for the SV40 enhancer activity in vitro. Nature (London) 313:458-463.

37. Scholer, H., and P. Gruss. 1985. Cell type specific transcriptional enhancement in vitro requires the presence of trans-acting factors. EMBO J. 4:3005-3013.

38. Sen, R., and D. Baltimore. 1986. Multiple nuclear factors interact with the immunoglobulin enhancers. Cell 46:705-716.

39. Serfling, E., M. Jasin, and W. Schaffiner. 1985. Enhancers and eukaryotic gene transcription. Trends Genet. 1:224-230.

40. Sergeant, A., D. Bohmann, H. Zentgraf, H. Weiher, and W. Keller. 1984. A transcriptional enhancer acts in vitro over distances of hundreds of base pairs on both circular and linear templates but not on chromatin reconstituted DNA. J. Mol. Biol. 180:577-600.

41. Singh, H., R. Sen, D. Baltimore, and P. A. Sharp. 1986. A nuclear factor that binds a conserved sequence motif in transcriptional control elements of immunoglobulin genes. Nature (London) 319:154-158.

42. Velcich, A., and E. Ziff. 1985. Adenovirus E1A proteins repress transcription from the SV40 early promoter. Cell 40:705-716.

43. Wabl, M., and P. D. Burrows. 1984. Expression of immunoglobulin heavy chain at a high level in the absence of a proposed immunoglobulin enhancer element in cis. Proc. Natl. Acad. Sci. USA 81:2452-2455.

44. Zaller, D. M., and L. A. Eckardt. 1985. Deletion of a B-cellspecific enhancer affects transfected, but not endogenous, immunoglobulin heavy-chain gene expression. Proc. Natl. Acad. Sci. USA 82:5088-5092.

45. Zimmerman, S. B., and. B. H. Pheiffer. 1983. Macromolecular crowding allows blunt-end ligations by DNA ligases from rat liver or Escherichia coli. Proc. Natl. Acad. Sci. USA 80: 5852-5856. 